\title{
Metformin and asarone inhibit HepG2 cell proliferation in a high glucose environment by regulating AMPK and Akt signaling pathway
}

\author{
Bhrigu Kumar Das ${ }^{1,2}$, Rachel M. Knott ${ }^{3}$ and Pramod C. Gadad ${ }^{1,2^{*}}$ (D)
}

\begin{abstract}
Background: Metabolic dysregulation is one of the hallmarks of tumor cell proliferation. Evidence indicates the potential role of the 5'adenosine monophosphate-activated protein kinase (AMPK) and protein kinase B/Akt signaling pathway in regulating cell proliferation, survival, and apoptosis. The present study explores the effect of metformin $\mathrm{HCl}$ and the combination of $\mathrm{a}$ - and $\beta$-asarone on the proliferation of $\mathrm{HepG} 2$ cells in the presence of high glucose levels simulating the diabetic-hepatocellular carcinoma (HCC) condition.

Results: The metformin and asarone reduced HepG2 cell viability in a dose-dependent manner and induced morphological changes as indicated by methyl thiazolyl tetrazolium (MTT) assay. The metformin and asarone arrested the cells at the $G_{0} / G_{1}$ phase, upregulated the expression of AMPK, and downregulated Akt expression in high glucose conditions as identified by the flow cytometry technique. Further, the upregulated AMPK led to a decrease in the expression of phosphoenolpyruvate carboxykinase-2 (PCK-2) and sterol regulatory element-binding protein-1 (SREBP-1).

Conclusion: The anti-proliferative effect of metformin and asarone in the diabetic-HCC condition is mediated via AMPK and Akt pathway.
\end{abstract}

Keywords: Asarone, Metformin HCl, HepG2 cells, High glucose, AMPK, Akt

\section{Background}

Epidemiologic evidence suggests diabetes mellitus (DM) as one of the potential risk factors in the progression of hepatocellular carcinoma (HCC) [1-3]. The complex pathophysiological relationship between HCC and DM could be due to hyperglycemia, hyperinsulinemia, insulin resistance, insulin-like growth factor (IGF)-1, obesity, or chronic inflammation with overlapping cell signaling

\footnotetext{
* Correspondence: gadadpramod@gmail.com

'Department of Pharmacology, KLE College of Pharmacy (A constituent unit of KLE Academy of Higher Education and Research, Belagavi), Vidyanagar, Hubballi, Karnataka 580 031, India

${ }^{2}$ Off-campus Basic and Applied Sciences Research Centre of KLE Academy of Higher Education and Research at KLE College of Pharmacy, Vidyanagar,

Hubballi, Karnataka 580 031, India

Full list of author information is available at the end of the article
}

pathways. The various signal transduction pathways are implied in uncontrolled proliferation, mutations, invasion, migration, and survival of the tumor cells $[4,5]$.

There are a growing number of studies that propose the 5 'adenosine monophosphate-activated protein kinase (AMPK), a highly conserved heterotrimeric serine/ threonine-protein kinase, is a crucial mediator as an energy sensor in all the eukaryotic cells [6]. It plays a vital role in maintaining cellular energy homeostasis in both diabetes and cancer growth $[7,8]$. Activation of the AMPK signaling pathway can influence changes in the effector's proteins involved in the regulatory process of energy metabolism, contributing to the pathogenesis of cancer [9-11]. Studies indicating AMPK activation correlates strongly with the reduction in cell proliferation in 
tumor cells as well as non-malignant cells. These effects are reported to be mediated through different mechanisms, including the modulation of cell cycle profile, autophagy, apoptosis, de novo fatty acid synthesis, and inhibition of protein synthesis $[12,13]$.

In addition to the AMPK signaling pathway, the Akt, a serine/threonine-protein kinase, also serves as an important pathway in multiple cellular processes that link with the increased proliferation, survival, and apoptosis of tumor cells $[14,15]$. The Akt also serves as a negative regulator of AMPK, and studies have shown that the increased expression of Akt can stimulate proliferation through multiple downstream regulations affecting the cell cycle [16].

There is a body of evidence suggesting that metformin reduces tumor growth directly through the inhibition of energy metabolism and by regulation of both AMPKdependent and independent signaling pathways [17-20]. On the other hand, alpha $(\alpha)$ - and beta $(\beta)$-asarone, the two major active constituents in volatile oils of Acorus calamus, showed anti-cancer effects in various cancer cell lines [21, 22]. Our previous study showed that asarone treatment attenuated the progression of HCC in diabetic conditions in a similar manner to that achieved by metformin [23]. The present study was aimed to understand whether the anti-proliferative effect of asarone is mediated via AMPK and Akt signaling pathway similar to the metformin, which was used as a reference drug. Further, we have also tried to address the possibility of the involvement of phosphoenolpyruvate carboxykinase2 (PCK-2) and sterol regulatory element-binding protein-1 (SREBP-1) with cancer cell growth.

\section{Methods}

\section{Drugs and reagents}

Alpha-asarone (Lot \# S18779; Purity 98\% w/w; PubChem CID: 636822) and beta-asarone (Lot \# STBF-1179 V; Purity 70\% w/w; PubChem CID: 5281758) was purchased from Sigma-Aldrich Chemical Company, USA. Metformin $\mathrm{HCl}$ (Lot No: METI-1710010; PubChem CID: 14219) was a gift sample from Angels Pharma India Pvt. Ltd. Hyderabad, India. Polyclonal fluorescein isothiocyanate (FITC) goat anti-rabbit secondary antibody IgG was obtained from BD Biosciences, USA (Catalog No. 554020; Lot \# 8199842). The primary rabbit polyclonal IgG antibodies viz., 5'adenosine monophosphateactivated protein kinase (AMPK $\alpha 1 ;$ Catalog no. orb10076; Lot \# A1227), protein kinase B (Akt; Catalog No. orb159889; Lot \# K8668), phosphoenolpyruvate carboxykinase-2 (PCK-2; Catalog no. orb5876; Lot \# A4509), and sterol regulatory element-binding protein-1 (SREBP-1; Catalog no. orb11415; Lot \# A1505) were purchased from Biorbyt Ltd., Cambridge, UK. Dulbecco's modified Eagle's medium (DMEM low and high glucose), fetal bovine serum (FBS) heat-inactivated, trypsin-ethylenediaminetetraacetic acid (EDTA) digestion solution $1 \times$, calcium- and magnesium-free phosphate-buffered saline (CMF-PBS), paraformaldehyde solution, methyl thiazolyl tetrazolium (MTT), and Triton X-100 were purchased from HiMedia Laboratories Pvt. Ltd., Mumbai, India. All other reagents used in this study were of cell culture grade obtained from commercial suppliers.

\section{Cell culture conditions}

The HCC cell line HepG2 (ATCC ${ }^{\bullet} \mathrm{HB}-8065^{\mathrm{mm}}$ ) was obtained and grown as recommended by the American Type Culture Collection (ATCC), USA. HepG2 cells were cultured in DMEM either in normoglycemic (5.5 $\mathrm{mM})$ or in hyperglycemic $(25 \mathrm{mM})$ glucose conditions depending upon the experiments that contained $10 \%$ FBS supplemented with $100 \mathrm{U} / \mathrm{ml}$ penicillin and $100 \mu \mathrm{g} /$ ml streptomycin (Sigma-Aldrich Chemical Company, USA) maintained at $37^{\circ} \mathrm{C}$ in an incubator (Labwit Scientific Pty Ltd., Australia).

\section{Cytotoxicity by MTT assay}

The cytotoxic effect of metformin $\mathrm{HCl}, \alpha$-asarone, and $\beta$-asarone on the HepG2 cell line was measured separately by the MTT assay [24]. Briefly, the cells were seeded in a 96-well flat-bottom plate ( $\mathrm{Nunc}^{\mathrm{mi}}$ MicroWell $^{\text {tw }}$, Thermo Fisher Scientific Inc., USA) with $200 \mu \mathrm{l}$ of cell suspension containing approximately 10,000 cells/ well and allowed to adhere by incubating for $24 \mathrm{~h}$ at $37^{\circ} \mathrm{C}$. After $24 \mathrm{~h}$, the medium was discarded and replaced with a fresh medium $(200 \mu \mathrm{l})$ containing different concentrations of metformin $\mathrm{HCl}(1.6,3.2,6.4,12.8$, and $25.6 \mathrm{mM})$ and $\alpha$ - and $\beta$-asarone $(0.12,0.24,0.48,0.96$, and $1.92 \mathrm{mM}$ ) followed by incubation for another $48 \mathrm{~h}$. Untreated cells were used as control. All the media was discarded, and $200 \mu \mathrm{l}$ of methyl thiazolyl tetrazolium (MTT) solution $(0.5 \mathrm{mg} / \mathrm{ml}$ in phosphate-buffered saline) was added to each well and incubated for $3 \mathrm{~h}$. Further, the MTT culture medium was removed without disturbing the crystals formed and $100 \mu \mathrm{l}$ of dimethyl sulfoxide (DMSO) was added to each well to solubilize formed formazan crystals. Absorbance was recorded at $570 \mathrm{~nm}$ using a microplate reader (Biobase ${ }^{\circ}$ EL-10A, China) to calculate the percent cell viability using the following formula:

$$
\text { Percent cell viability }=\frac{(\mathrm{At}-\mathrm{Ab})}{(\mathrm{Ac}-\mathrm{Ab})} \times 100
$$

where At is the absorbance value of the test compounds (metformin and asarone), Ab is the absorbance value of the blank, and Ac is the absorbance value of the control (untreated cells). 
Table 1 The $\mathrm{IC}_{50}$ values of metformin $\mathrm{HCl}$ and $\mathrm{a}$ - and $\beta$-asarone based on the MTT assay and dose selected for further studies

\begin{tabular}{lll}
\hline Test compounds & $\mathbf{I C}_{\mathbf{5 0}}$ values in $\mathbf{~ m M}$ (MTT assay) & One half of the $\mathbf{I C}_{\mathbf{5 0}}$ in $\mathbf{m M}$ used for detailed studies \\
\hline Metformin $\mathrm{HCl}$ & 25.74 & 12.87 \\
a-Asarone & 1.22 & 0.61 \\
$\beta$-Asarone & 1.46 & 0.73 \\
\hline
\end{tabular}

Further, the percent of the cell viability against the concentration of each test compound was plotted and the inhibitory concentration $50\left(\mathrm{IC}_{50}\right)$ value was generated from the dose-response curve.

\section{Experimental study design}

The $\mathrm{IC}_{50}$ values of metformin $\mathrm{HCl}$ and $\alpha$ - and $\beta$-asarone were $12.87,0.61$, and $0.73 \mathrm{mM}$, respectively, and this represents one half of the $\mathrm{IC}_{50}$ value generated from the MTT assay (Table 1). Further, the HepG2 cells were divided into four groups: the normoglycemic (NG) cultured in normal glucose of $5.5 \mathrm{mM}$, the hyperglycemic (HG) cultured in high glucose of $25 \mathrm{mM}$, the HG group treated with metformin $\mathrm{HCl}(12.87 \mathrm{mM})$, and the HG group treated with a combined dose of asarone $(0.61$ $\mathrm{mM}(\alpha)$-asarone; $0.73 \mathrm{mM}(\beta)$-asarone).

\section{Cell cycle analysis}

The phases of the cell cycle were analyzed by measuring the amount of propidium iodide (PI)-labeled DNA staining in ethanol-fixed cells, as described elsewhere [25]. In brief, HepG2 cells $\left(5 \times 10^{5}\right.$ cells/well $)$ were seeded in a 6-well plate ( $\mathrm{Nunc}^{\mathrm{Tw}}$, Thermo Fisher Scientific Inc., USA) and allowed to adhere for $24 \mathrm{~h}$ at $37^{\circ} \mathrm{C}$. Thereafter, fresh DMEM medium containing 10\% FBS was cultured with NG, HG, HG + Metformin, and HG + Asarone for $16 \mathrm{~h}$. Subsequently, the trypsinized cells were fixed $(70 \%$ chilled ethanol at $4{ }^{\circ} \mathrm{C}$ for $30 \mathrm{~min}$ ), stained with PIRNase solution (BD Biosciences, USA), and incubated at room temperature in the dark for $30 \mathrm{~min}$. Further, the stained cells were collected and mixed well for analysis. A cytomics FC500 flow cytometer (Beckman-Coulter, USA) equipped with CXP software was used to collect the data. The analysis of results was made by measuring the forward scatter (FS) and side scatter (SS) for the identification of the single cells. Further, pulse shape processing was enabled to exclude all the clumps and doublet cells for the analysis by using pulse area vs. pulse width depending upon the experiment. Finally, the data were evaluated by using an algorithm (fit Gaussian curves) available in the FlowJo v10.0.7 software, and the PI-stained histogram plots represent the percentage of
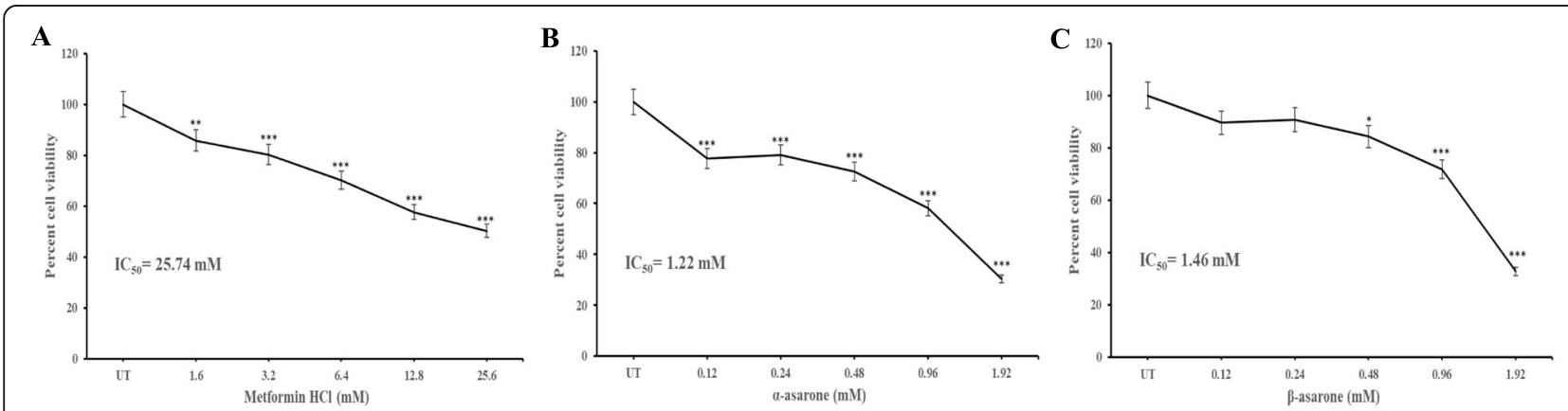

D
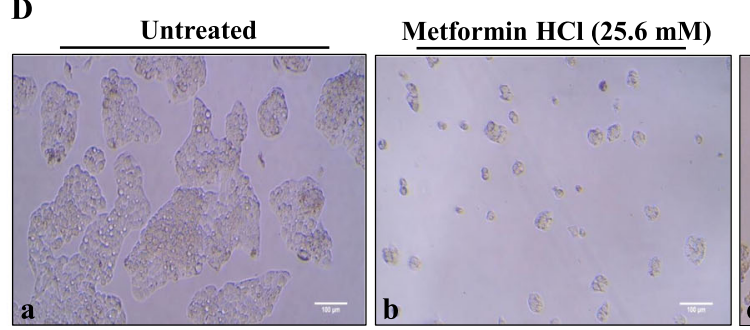

$\alpha$-asarone (1.92 mM)

B-asarone (1.92 mM)

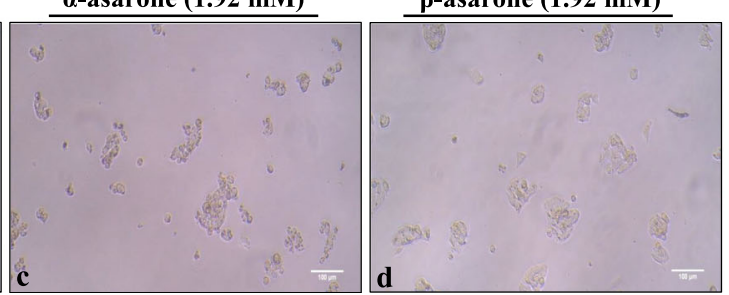

Fig. 1 Metformin and asarone inhibit the growth and modify the morphology of HepG2 cells. A-C Cells were treated with metformin HCl, aasarone, and $\beta$-asarone as indicated for $48 \mathrm{~h}$ and the cell viability was determined by MTT assay. D Representative images to show the morphology of HepG2 cells under an inverted microscope. The scale of the bar is $100 \mu \mathrm{m}$. a Untreated group; the morphology of HepG2 cells had a high density with adherent cell colonies, whereas, in the treatment group, metformin $\mathrm{HCl}(\mathrm{b})$ and asarone (c, d) at higher concentration showed lower density with a small round body. Values represent mean \pm SEM of an experiment done in triplicate; one-way ANOVA followed by Bonferroni test, where ${ }^{*} p<0.05,{ }^{* *} p<0.01$, and ${ }^{* * *} p<0.001$ compared to the untreated (UT) group 


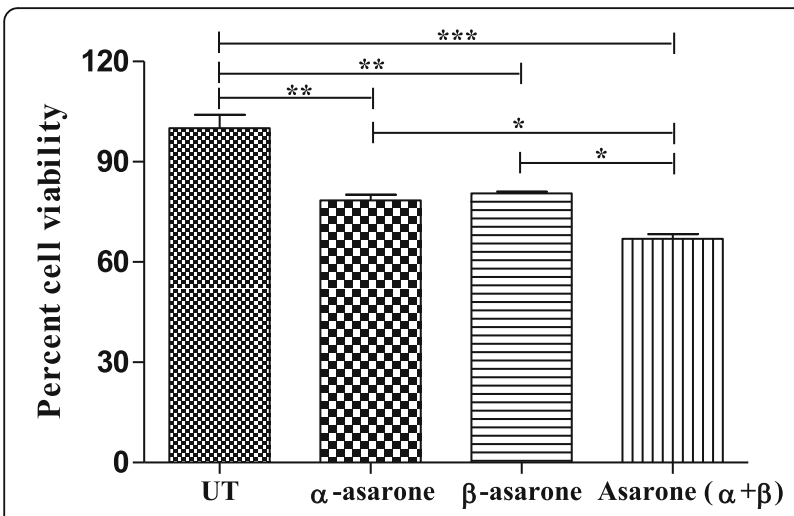

Fig. 2 The combined cell viability activity of $\alpha+\beta$-asarone $(0.61 \mathrm{mM}$ $+0.73 \mathrm{mM}$ ) was more effective than the single entity of either $\mathrm{a}$ - or $\beta$-asarone $(0.61 \mathrm{mM}$ or $0.73 \mathrm{mM})$ when compared to the untreated (UT) group. Values represent mean \pm SEM of an experiment done in triplicate; one-way ANOVA followed by Bonferroni test, where * $p<$ $0.05,{ }^{* *} p<0.01$, and ${ }^{* * *} p<0.001$ when compared as indicated

cells in different phases of the cell cycle of an experiment.

\section{Expression of AMPKa1, Akt, PCK-2, and SREBP-1}

The quantitative analysis of the expression of the intracellular markers was performed by flow cytometry using a 6-well plate. The cells were cultured at a density of $3 \times$ $10^{5}$ cells $/ 2 \mathrm{ml}$ and allowed to adhere for $24 \mathrm{~h}$ at $37^{\circ} \mathrm{C}$.
The next day, the medium was discarded and washed with $1000 \mu \mathrm{l}$ of $1 \times$ phosphate-buffered saline (PBS) and the cells were treated with metformin and asarone; if not, they are served as a control. The drug-treated media were removed from all the wells, transferred into a 5-ml centrifuge tube, and washed with $500 \mu \mathrm{l} \mathrm{PBS}$. The PBS was then removed and transferred to the same centrifuge tube. Further, $200 \mu \mathrm{l}$ of the trypsin-EDTA solution was added to all the wells and incubated for $4 \mathrm{~min}$ at $37^{\circ} \mathrm{C}$. Finally, the cells were harvested directly into the centrifuge tube after transferring back the medium from the respective wells. Thereafter, the cells containing the media were centrifuged at $300 \times g$ at $25^{\circ} \mathrm{C}$ for $5 \mathrm{~min}$. The supernatant was decanted carefully, treated with $500 \mu \mathrm{l}$ of $2 \%$ paraformaldehyde (PFA) solution, and incubated for $20 \mathrm{~min}$ at room temperature. Cells were further mixed with $1000 \mu \mathrm{l}$ of $1 \times$ PBS to dilute PFA solution and centrifuged at $300 \times g$ at $25^{\circ} \mathrm{C}$ for $5 \mathrm{~min}$. After decanting the supernatant, cells were permeabilized by treatment with $500 \mu \mathrm{l}$ of $0.1 \%$ Triton X-100, mixed well, and incubated for another $10 \mathrm{~min}$. Afterwards, cells were mixed with $1000 \mu \mathrm{l}$ of $0.5 \% \mathrm{BSA}$ solution for settlement and centrifuged at $200 \times g$ at $25^{\circ} \mathrm{C}$ for $5 \mathrm{~min}$ and the supernatant was decanted. Further, $0.5 \%$ BSA solution in $1 \times$ PBS was added with $6 \mu \mathrm{l}$ of primary antibody (AMPK $\alpha 1$, Akt, PCK-2, and SREBP-1) not exceeding the final volume more than $100 \mu \mathrm{l}$, mixed well, and

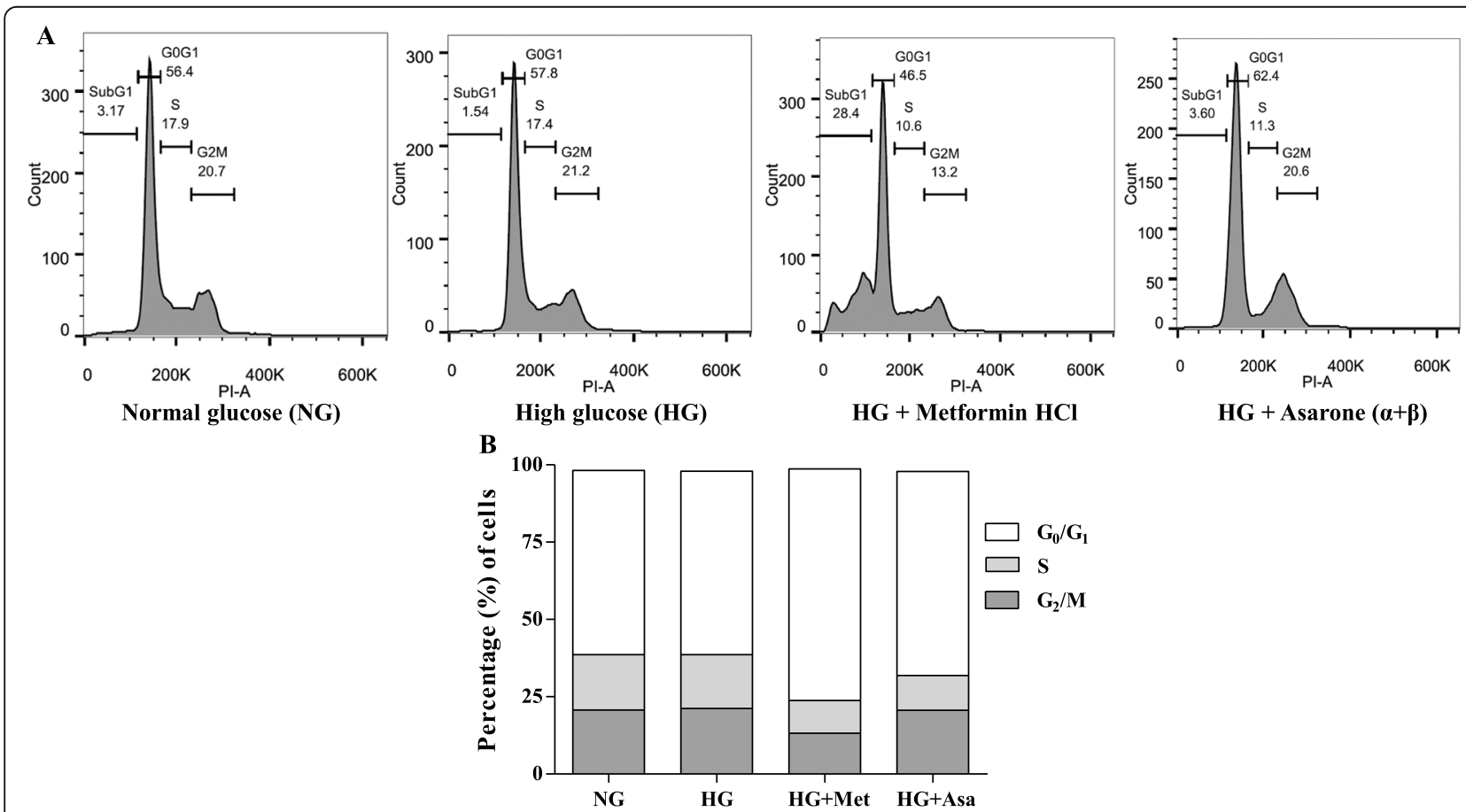

Fig. 3 Metformin and asarone block HepG2 cells in $G_{0} / G_{1}$ phase in hyperglycemic condition a Cell cycle profile of HepG2 cells cultured in normal glucose (NG; $5.5 \mathrm{mM}$ ), high glucose ( $\mathrm{HG} ; 25 \mathrm{mM}$ ), $\mathrm{HG}+$ Metformin $\mathrm{HCl}$, and $\mathrm{HG}+$ Asarone for $16 \mathrm{~h}$ and stained with PI-RNase was determined by flow cytometry. $\mathbf{b}$ Bar diagrams represent the percentage (\%) of cells in different phases of the cell cycle 
incubated at $25^{\circ} \mathrm{C}$ for $1 \mathrm{~h}$. After incubation, it was washed with $0.5 \%$ BSA solution, resuspended with $500 \mu \mathrm{l}$ of $0.5 \% \mathrm{BSA}$ in $1 \times \mathrm{PBS}$, and added with $6 \mu \mathrm{l}$ of the secondary antibody and incubated. After $1 \mathrm{~h}$ of incubation in a dark room at $25^{\circ} \mathrm{C}$, cells were centrifuged and decanted. Finally, cells were resuspended in $500 \mu \mathrm{l}$ of $0.5 \%$ BSA, mixed well, and analyzed. A cytomics FC500 flow cytometer (Beckman-Coulter, USA) equipped with CXP software was used to collect the data. The analysis of the results was carried out, as explained previously. The higher the value of geometric mean fluorescence intensity (GMFI), the higher the expression of individual markers of the cells as a population.

\section{Statistical analysis}

Statistical analysis was performed using statistical software GraphPad Prism version 6.0 (GraphPad Software, San Diego, CA, USA). Data from the individual experiments are represented as mean \pm SEM and were conducted in triplicate. The results obtained were analyzed using one-way analysis of variance (ANOVA) followed by Bonferroni multiple comparison test, and $p<0.05$ were considered as significant.

\section{Results}

Metformin and asarone inhibit the growth and modify the morphology of HepG2 cells

Metformin $\mathrm{HCl}$ (1.6 to $25.6 \mathrm{mM}), \alpha$-asarone (0.12 to $1.92 \mathrm{mM}$ ), and $\beta$-asarone (0.48 to $1.92 \mathrm{mM}$ ) inhibited the cell viability of HepG2 cells in a concentrationdependent manner compared to untreated cells (Fig. 1AC). The original morphology of the cells in the untreated group had a high density with adherent cell colonies, wherein few cells piled up, with a multilayered appearance. Following treatment with metformin $\mathrm{HCl}, \alpha-$ asarone, and $\beta$-asarone, the cell morphology was characterized by low density, small round bodies due to shrinkage and the detachment of non-viable cells in a dosedependent manner (Fig. 1D). The results are representative of experiments performed on three different occasions.

\section{The combined effect of $\alpha$ - and $\beta$-asarone inhibits the cell proliferation}

The corresponding MTT results showed that the cell proliferation of $\alpha$ - or $\beta$-asarone was inhibited compared to the untreated cells $(p<0.01)$ and that the combined effect of $\alpha$ - and $\beta$-asarone $(0.61 \mathrm{mM}+0.73 \mathrm{mM})$ was

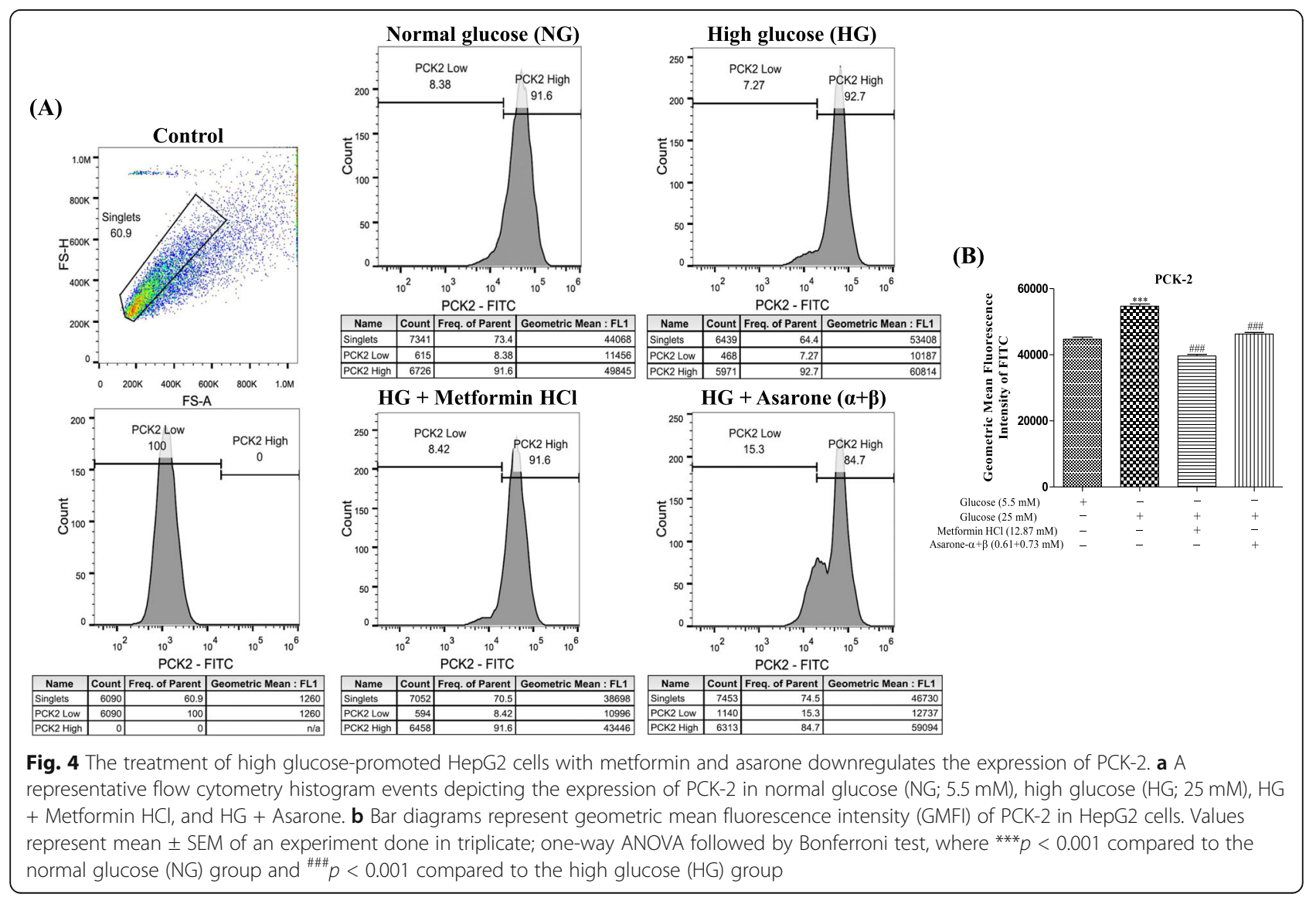


better $(p<0.05)$ than the single effect of $\alpha$ - or $\beta$-asarone (0.61 $\mathrm{mM}$ or $0.73 \mathrm{mM}$ ) (Fig. 2).

\section{Metformin and asarone block HepG2 cells in the $\mathrm{G}_{0} / \mathrm{G}_{1}$ phase in hyperglycemic condition}

We observed that in HepG2 cells, the percentage of the cells in the sub $G_{1}$ phase was less in high glucose than in normal glucose. Metformin and asarone treatment arrested the cells in the $G_{0} / G_{1}$ phase and reduced the cell count in S-phase cultured in high glucose concentration. Further, metformin retained the cells in the sub $\mathrm{G}_{1}$ population stage (Fig. 3a, b). These results indicate that metformin and asarone inhibit cell proliferation at the $G_{0} / G_{1}$ phase of the cell cycle.

\section{Metformin and asarone inhibit the expression of PCK-2 and SREBP-1 via the AMPKa1 pathway}

Based on the observation that metformin and asarone treatment induces the cytotoxicity of HepG2 cells in high glucose conditions, we measured whether this is a consequence of altered cellular energy homeostasis. The PCK-2 and SREBP-1 are the downstream regulators in the AMPK pathway, which regulate gluconeogenesis, glucose uptake, and de novo lipogenesis. Flow cytometry analysis revealed that AMPK $\alpha 1$ expression was enhanced by both metformin and asarone. Figures 4, 5, and 6 indicate the flow cytometry histogram events and geometric mean fluorescence intensity (GMFI) depicting the expression of respective markers in HepG2 cells. A significant increase in the expression of AMPK $\alpha 1$ was observed indicated by the increase in the GMFI for metformin $(p<0.01)$ and asarone $(p<0.001)$ compared with the negative control (Fig. 6). Further, it was observed that the expression of PCK-2 $(p<0.001 ; p<0.001)$ and SREBP-1 $(p<0.01 ; p<0.001)$ decreased in the metformin- and asarone-treated groups (Figs. 4 and 5).

\section{Metformin and asarone decrease the expression of Akt}

The phosphatidylinositol 3-kinase/protein kinase B (PI3K/Akt), a prototypic signaling pathway, is increasingly implicated in carcinogenesis and plays a key role in the regulation of the growth and proliferation of cells. The change in the glucose concentration did not have any effect on the expression of Akt in HepG2 cells. However, a significant decrease in the expression levels of Akt was observed in metformin $(p<0.01)$ and asarone $(p<0.001)$ groups compared to untreated cells as indicated by GMFI (Fig. 7).
(A)
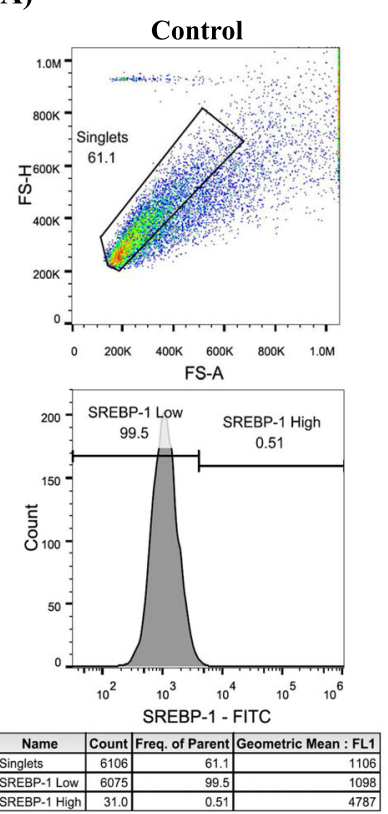
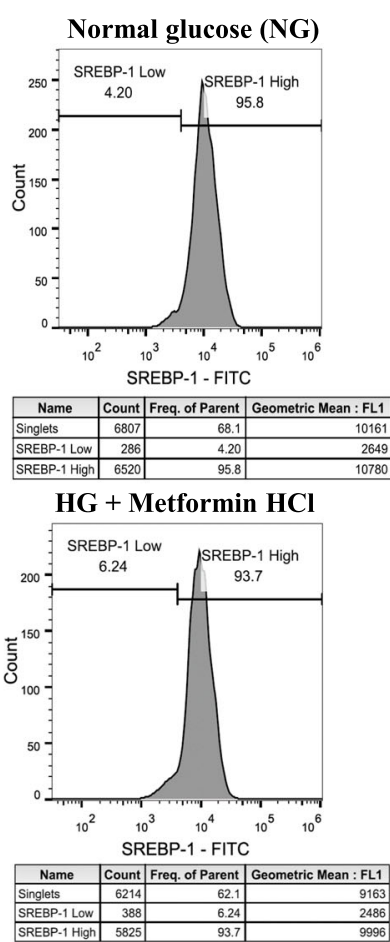

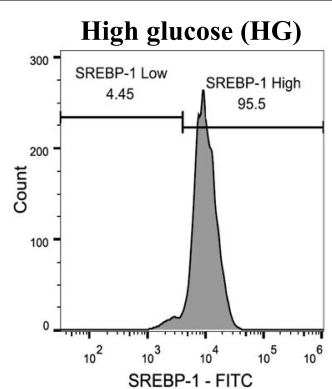

(B)
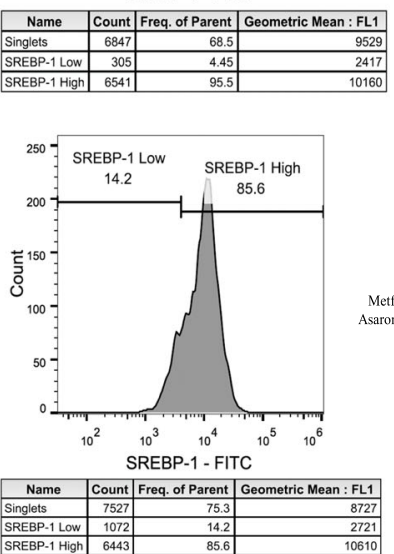

SREBP-1

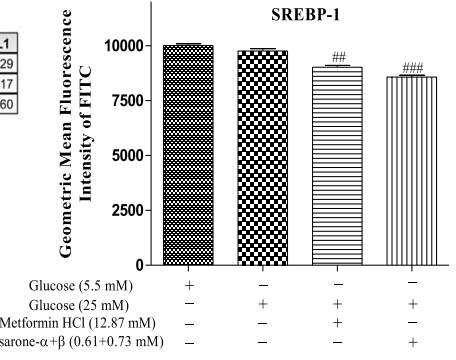

Fig. 5 The treatment of high glucose-promoted HepG2 cells with metformin and asarone downregulates the expression of SREBP-1. a A representative flow cytometry histogram events depicting the expression of SREBP-1 cultured in normal glucose (NG; 5.5 mM), high glucose (HG; $25 \mathrm{mM}$ ), HG + Metformin HCl, and HG + Asarone. b Bar diagrams represent geometric mean fluorescence intensity (GMFI) of SREBP-1 in HepG2 cells. Values represent mean \pm SEM of an experiment done in triplicate; one-way ANOVA followed by Bonferroni test, where ${ }^{\# \#} p<0.01$ and ${ }^{\# \# \# ~}<$ 0.001 compared to the high glucose $(\mathrm{HG})$ group 


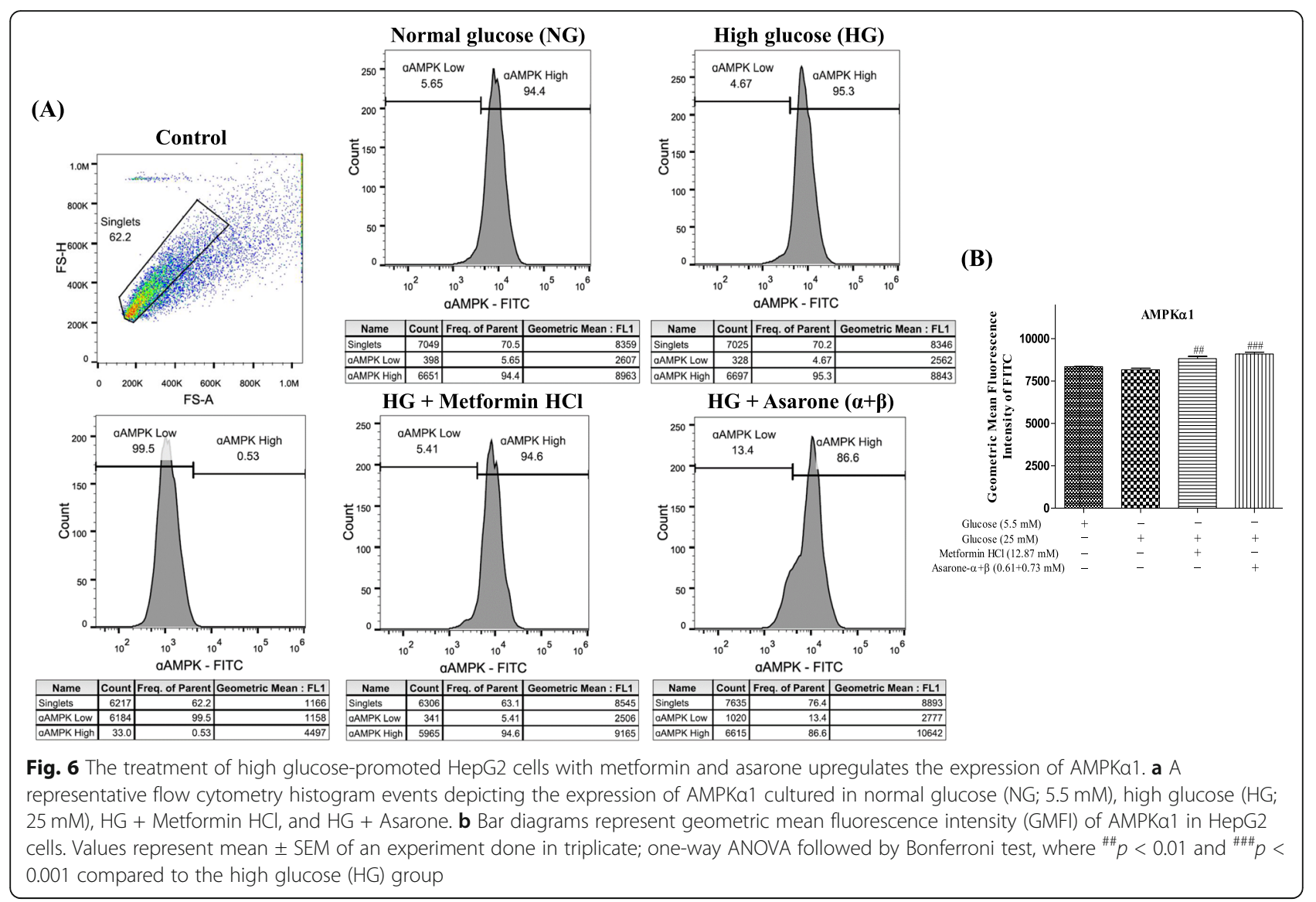

\section{Discussion}

Many experimental as well as epidemiological studies suggest that the higher plasma glucose level might play a crucial role in cancer development and progression [2629]. However, the involvement of regulatory pathways between the effect of hyperglycemia (HG) and hepatic cancer remains largely unexplored. In the present study, we attempted to explore the effect of metformin and asarone in abating the proliferation of HepG2 cells in high glucose conditions. The results of this study suggest that metformin and asarone suppress the hepatic cancer cell viability and arrested the cell cycle at the $G_{0} / G_{1}$ phase by AMPK activation and Akt inhibition.

Studies, including our own, suggest that higher blood glucose concentration may be associated with the increased risk of cancers [23, 30-33]. The increased proliferation of HepG2 cells at elevated glucose levels may be due to glucose toxicity resulting from increased production of reactive oxygen species (ROS) and alteration in the expression of genes $[4,34]$. Other work reported that this could be due to a favorable environment for the cancer-signaling pathway leading to proliferation, mutations, invasion, migration, and survival [4]. The AMPK and Akt signaling pathways, along with their downstream regulators, are indicated to play an important role in the regulation of cancer as well as glucose metabolism [35].

Classically, the 5'adenosine monophosphate-activated protein kinase (AMPK) has been identified as a central metabolic sensor playing a significant role in energy homeostasis. However, the emerging evidence suggests AMPK is a possible metabolic tumor suppressor and has been implicated in preventing and treating tumor growth [36-38]. The AMPK activation can regulate various tissue- and cell-specific downstream markers responsible for proliferation, autophagy, and apoptosis [12, $13,39]$. The observed anti-proliferative actions of metformin and asarone in a high glucose environment and changes of AMPK $\alpha 1$ expression are in accordance with many other studies that correlate with AMPK activation and inhibition of tumor growth [9-11]. These findings suggest that the HepG2 cell line proliferation is inversely correlated to AMPK activity in high glucose conditions.

The evidence indicates the altered expression of gluconeogenic enzymes during HCC growth and differentiation, in particular, the phosphoenolpyruvate carboxykinase (PCK or PEPCK) genes. The metformin and asarone treatment decreased the expression of PCK2 (a downstream regulator of AMPK), a gluconeogenic factor in the liver that plays a role in the regulation of 


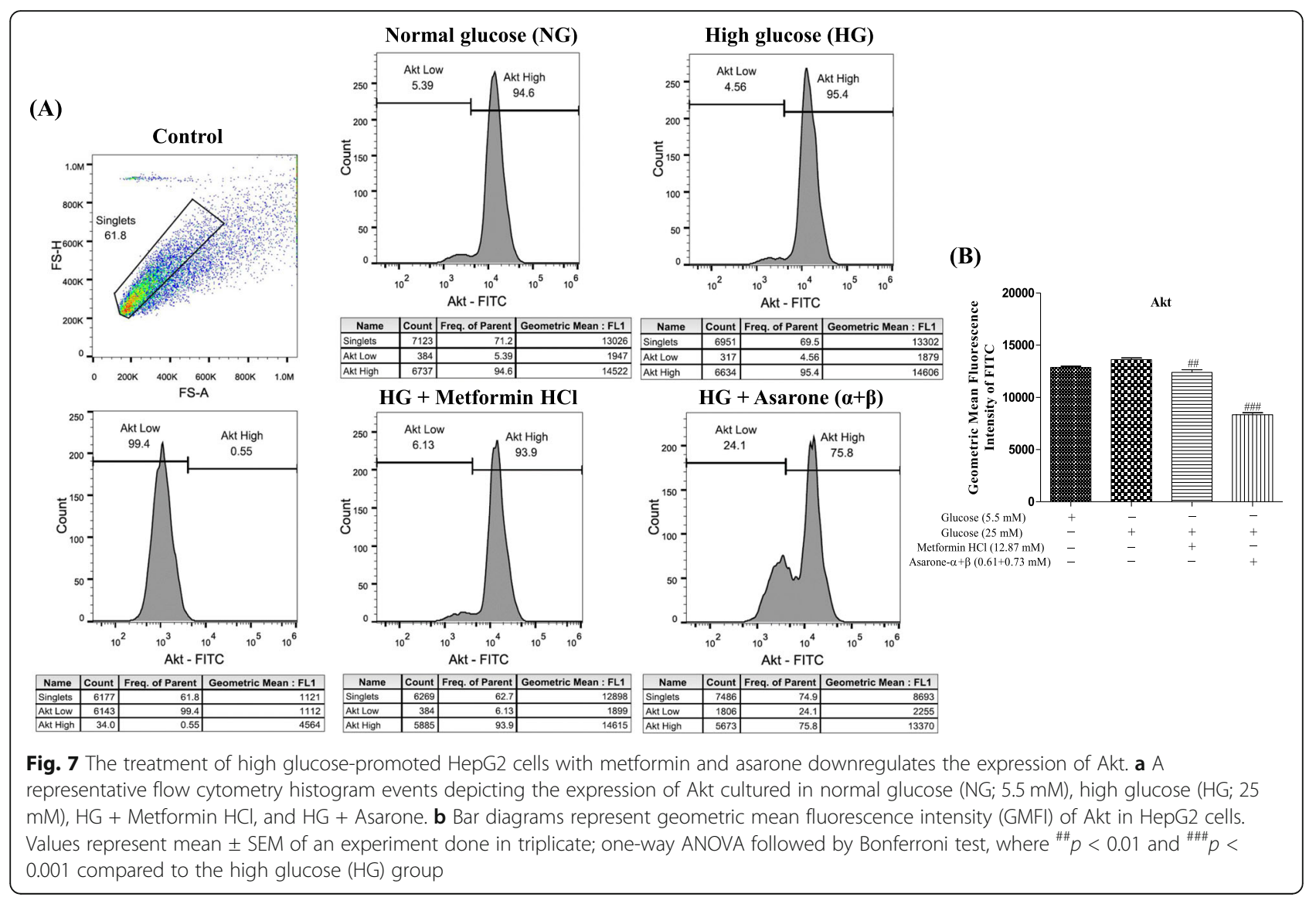

the gluconeogenesis process by catalyzing the conversion of oxaloacetate (OAA) to phosphoenolpyruvate (PEP) [40, 41]. Elevated expression of the PCK-2 gene is found in different cancers and is linked to increased anabolic metabolism, thereby playing a vital role in cancer cell proliferation $[42,43]$. The observed upregulation of PCK-2 expression in our study could be due to an increase in glucose uptake and utilization, supporting the anabolic metabolism and promoting cell proliferation. In contrast, the expression of PCK-2 in the metformin and asarone treatment was downregulated, indicating the involvement of the glucose metabolism pathway in suppressing the growth of cancer cells. The earlier work suggested the role of PCK or PEPCK in increasing the glutamine and glucose concentration, thus linking anabolic pathways to cancer cell proliferation both in vivo and in vitro [44]. Furthermore, Akt also regulates the PCK or PEPCK expression mediated through phosphorylation of cyclic AMP response element-binding/Forkhead box protein O1 (CREB/ FOXO1) transcriptional activity [45].

Furthermore, both AMPK and Akt are the upstream regulator of sterol regulatory element-binding protein-1 (SREBP-1) and can directly phosphorylate SREBP-1. Recently, SREBP-1, which gets upregulated in different types of cancer, has been linked to play a role in the oncogenic signaling-mediated glucose uptake and de novo lipogenesis [46-48]. The pharmacological targeting of SREBP-1 has revealed to significantly inhibit the glioblastoma cell growth, suggesting it as a novel molecular target in cancer [49]. In addition to regulation by AMPK, SREBP-1 has shown to be activated by the Akt/PI3K prototypic survival signaling pathway in different types of cancer. Collectively, it demonstrated the role of the Akt/PI3K signaling pathway via SREBP-1 integrating lipogenesis and glucose metabolism for rapid cancer progression [49-51]. In our study too, metformin and asarone decreased SREBP-1 expression in a high glucose-induced proliferation of HepG2 cells, indicating the involvement of the AMPK/SREBP-1 or Akt/SREBP-1 signaling pathway.

The deregulation of the Akt/PI3K prototypic survival signaling pathway also plays an important role in cell proliferation. Evidence indicates that abnormal activation of the Akt/PI3K signaling pathway frequently occurs in HCC patients [14-16]. In this study, metformin and asarone treatment significantly decreased the expression level of Akt, thereby suppressing HepG2 cell proliferation. These findings are supported by other workers who suggest that metformin inhibited the growth of various cancer cells through inhibition of Akt [52-54]. 


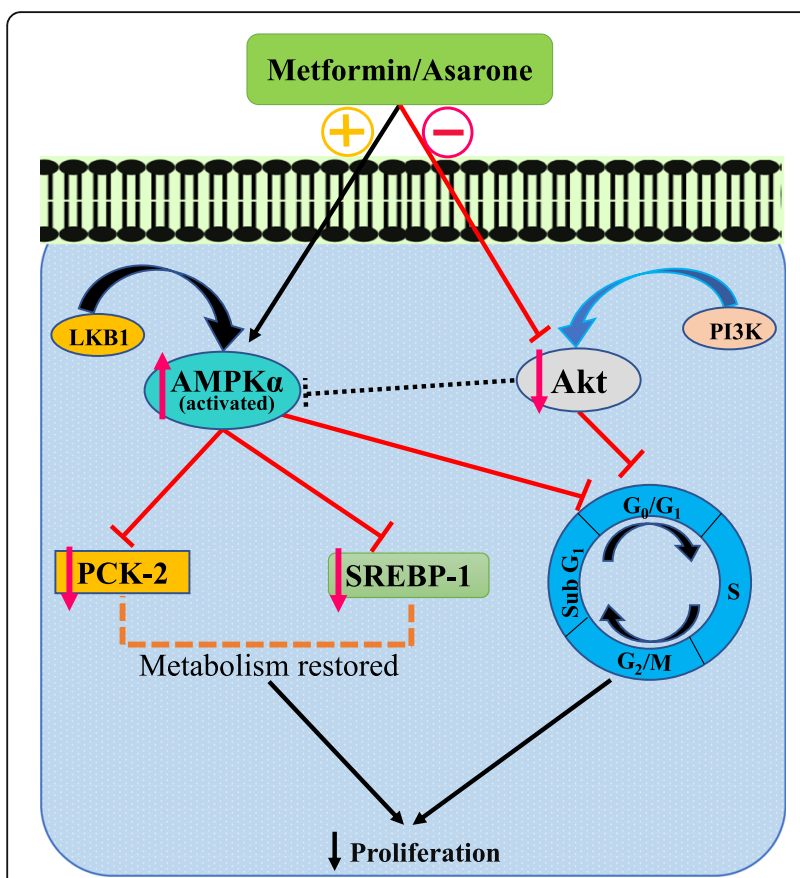

Fig. 8 Schematic representation of the mechanism by which metformin and asarone cause $G_{0} / G_{1}$ arrest by regulation of AMPK via PCK-2 and SREBP-1 as well as Akt signaling pathway in a high glucose environment in HepG2 cells

The observed antagonistic relationship between AMPK and Akt and their impact on the proliferation of cancer cells is in concurrence with earlier studies by other workers. The Akt/PI3K mediated carcinogenesis and tumor progression gets upregulated due to the mammalian target of rapamycin (mTOR) signaling pathway, which in turn is activated due to deregulation of the AMPK [35, $55,56]$. Besides this, the deregulation of the AMPK disturbs the insulin signaling pathway and results in elevated levels of insulin-like growth factor-1/insulin, a common pathway for both HCC and diabetic conditions [57].

\section{Conclusion}

The metformin and asarone inhibit the HepG2 cancer cell proliferation, specifically at the $G_{0} / G_{1}$ phase of the cell cycle in a high glucose environment, which is attributable to the regulation of AMPK and Akt signaling pathways (Fig. 8). Further, the inhibition of PCK-2 and SREBP-1 indicates the link between the glucose metabolic pathway and cancer cell growth. However, the potential limitations of the study include the possibility of adopting other molecular biological methods to verify our findings, along with the role of specific activators or inhibitors in high glucose-induced HepG2 cell proliferation through modulation of both the AMPK and Akt signaling pathways. Further, the investigation about the possibility of involvement of multiple pathways is essential to elucidate the molecular mechanism/s of metformin and asarone in controlling the progression of cancer.

\section{Abbreviations}

AMPK: 5'Adenosine monophosphate-activated protein kinase; BSA: Bovine serum albumin; DM: Diabetes mellitus; DMEM: Dulbecco's modified Eagle's medium; FBS: Fetal bovine serum; GMFI: Geometric mean fluorescence intensity; HCC: Hepatocellular carcinoma; HG: Hyperglycemic/high glucose; MTT: Methyl thiazolyl tetrazolium; NG: Normoglycemic/normal glucose; PCK2: Phosphoenolpyruvate carboxykinase-2; PBS: Phosphate-buffered saline; PFA: Paraformaldehyde solution; PI3K: Phosphatidylinositol 3-kinase; SREBP1: Sterol regulatory element-binding protein-1

\section{Acknowledgements}

The authors acknowledge CellKraft Biotech Pvt. Ltd. Bangalore, Karnataka, India, for providing the facilities to conduct the research study.

\section{Authors' contributions}

BKD and PCG designed all the experiments and wrote the manuscript. BKD has investigated the experiments and analyzed the data. RMK has reviewed and edited the manuscript. PCG was associated with supervising, advising, reviewing, and editing the final version of the manuscript. All the authors have read and approved the final manuscript.

\section{Funding}

No funding was sourced.

\section{Availability of data and materials}

All data and materials are available upon request.

Ethics approval and consent to participate Not applicable.

\section{Consent for publication}

Not applicable.

\section{Competing interests}

The authors declare no competing interests.

\section{Author details}

${ }^{1}$ Department of Pharmacology, KLE College of Pharmacy (A constituent unit of KLE Academy of Higher Education and Research, Belagavi), Vidyanagar, Hubballi, Karnataka 580 031, India. ${ }^{2}$ Off-campus Basic and Applied Sciences Research Centre of KLE Academy of Higher Education and Research at KLE College of Pharmacy, Vidyanagar, Hubballi, Karnataka 580 031, India. ${ }^{3}$ School of Pharmacy and Life Sciences, Robert Gordon University, Aberdeen AB10 7GJ, UK.

Received: 7 September 2020 Accepted: 21 January 2021 Published online: 12 February 2021

\section{References}

1. Davila JA, Morgan RO, Shaib Y, McGlynn KA, El-Serag HB (2005) Diabetes increases the risk of hepatocellular carcinoma in the United States: a population-based case control study. Gut 54:533-539

2. Vecchia CA, Negri E, Decarli A, Franceschi S (1997) Diabetes mellitus and the risk of primary liver cancer. Int J Cancer 73:204-207

3. Yuan JM, Govindarajan S, Arakawa K, Yu MC (2004) Synergism of alcohol, diabetes, and viral hepatitis on the risk of hepatocellular carcinoma in blacks and whites in the U.S. Cancer 101:1009-1017

4. Jimenez CG, Garcia-Martinez JM, Chocarro-Calvo A, De la Vieja A (2014) A new link between diabetes and cancer: enhanced WNT/b-catenin signaling by high glucose. J Mol Endo 52:R51-R66

5. Giovannucci E, Harlan DM, Archer MC, Bergenstal RM, Gapstur SM, Habel LA et al (2010) Diabetes and cancer: a consensus report. CA Cancer J Clin 60: 207-221

6. Hardie DG, Carling D, Carlson M (1998) The AMP-activated/SNF1 protein kinase subfamily: metabolic sensors of the eukaryotic cell? Annu Rev Biochem 67:821-855

7. Jones RG, Thompson CB (2009) Tumor suppressors and cell metabolism: a recipe for cancer growth. Genes Dev 23:537-548

8. Li Cl, Chen HJ, Lai HC, Liu CS, Lin WY, Li TC et al (2015) Hyperglycemia and chronic liver diseases on risk of hepatocellular carcinoma in Chinese 
patients with type 2 diabetes-National cohort of Taiwan Diabetes Study. Int J Cancer 136:2668-2679

9. Li W, Saud SM, Young MR, Chen G, Hua B (2015) Targeting AMPK for cancer prevention and treatment. Oncotarget 6:7365-7378

10. Shackelford DB, Shaw RJ (2009) The LKB1-AMPKpathway: metabolism and growth control in tumor suppression. Nat Rev Cancer 9:563-575

11. Mihaylova MM, Shaw RJ (2011) The AMPK signaling pathway coordinates cell growth, autophagy and metabolism. Nat Cell Biol 13:1016-1023

12. Motoshima H, Goldstein BJ, Igata M, Araki E (2006) AMPK and cell proliferation-AMPK as a therapeutic target for atherosclerosis and cancer. J Physiol 574:63-71

13. Liang J, Shao SH, Xu ZX, Hennessy B, Ding Z, Larrea M et al (2007) The energy sensing LKB1-AMPK pathway regulates p27(kip1) phosphorylation mediating the decision to enter autophagy or apoptosis. Nat Cell Bio 9:218-224

14. Manning BD, Cantley LC (2007) AKT/PKB signaling: navigating downstream. Cell 129:1261-1274

15. Vivanco I, Sawyers CL (2002) The phosphatidylinositol 3-kinase AKT pathway in human cancer. Nat Rev Cancer 2:489-501

16. Zhou Q, Lui VWY, Yeo W (2011) Targeting the PI3K/Akt/mTOR pathway in hepatocellular carcinoma. Future Oncol 7:1149-1167

17. Zhang H, Gao C, Fang L, Zhao HC, Yao SK (2013) Metformin and reduced risk of hepatocellular carcinoma in diabetic patients: a meta-analysis. Scand J Gastroenterol 48:78-87

18. DePeralta DK, Wei L, Ghoshal S, Schmidt B, Lauwers GY, Lanuti M et al (2016) Metformin prevents hepatocellular carcinoma development by suppressing hepatic progenitor cell activation in a rat model of cirrhosis. Cancer 122:1216-1227

19. Zhou G, Myers R, Li Y, Chen Y, Shen X, Fenyk-Melody J et al (2001) Role of AMP-activated protein kinase in mechanism of metformin action. J Clin Invest 108:1167-1174

20. Saraei P, Asadi I, Kakar MA, Moradi-Kor N (2019) The beneficial effects of metformin on cancer prevention and therapy: a comprehensive review of recent advances. Cancer Manag Res 11:3295-3313

21. Das BK, Swamy AHMV, Koti BC, Gadad PC (2019) Experimental evidence for use of Acorus calamus (asarone) for cancer chemoprevention. Heliyon 5:e01585

22. Chellian R, Pandy V, Mohamed Z (2017) Pharmacology and toxicology of aand $\beta$-asarone: a review of preclinical evidence. Phytomedicine 32:41-58

23. Das BK, Choukimath SM, Gadad PC (2019) Asarone and metformin delays experimentally induced hepatocellular carcinoma in diabetic milieu. Life Sci 230:10-18

24. Bahuguna A, Khan I, Bajpai V, Kang S (2017) MTT assay to evaluate the cytotoxic potential of a drug. Bangladesh J Pharm 12:115-118

25. Pozarowski P, Darzynkiewicz Z (2004) Analysis of cell cycle by flow cytometry. Methods Mol Biol 281:301-311

26. Laguna JC, Alegret M, Roglans N (2014) Simple sugar intake and hepatocellular carcinoma: epidemiological and mechanistic insight. Nutrients 6:5933-5954

27. Stattin P, Bjor O, Ferrari P, Lukanova A, Lenner P, Lindahl B et al (2007) Prospective study of hyperglycemia and cancer risk. Diabetes Care 30:561-567

28. Han H, Zhang T, Jin Z, Guo H, Wei X, Liu Y et al (2017) Blood glucose concentration and risk of liver cancer: systematic review and meta-analysis of prospective studies. Oncotarget 8:50164-50173

29. Duan W, Shen X, Lei J, Xu Q, Yu Y, Li R et al (2014) Hyperglycemia, a neglected factor during cancer progression. Biomed Res Int 2014:461917

30. Park EJ, Lee JH, Yu GY, He G, Ali SR, Holzer RG et al (2010) Dietary and genetic obesity promote liver inflammation and tumorigenesis by enhancing IL-6 and TNF expression. Cell 140:197-208

31. Pollak M (2009) Do cancer cells care if their host is hungry? Cell Metab 9: 401-403

32. Algire C, Zakikhani M, Blouin MJ, Shuai JH, Pollak M (2008) Metformin attenuates the stimulatory effect of a high-energy diet on in vivo LLC carcinoma growth. Endor Relat Cancer 15:833-839

33. Santisteban GA, Ely JT, Hamel EE, Read DH, Kozawa SM (1985) Glycemic modulation of tumor tolerance in a mouse model of breast cancer. Biochem Biophys Res Commun 132:1174-1179

34. Masur K, Vetter C, Hinz A, Tomas N, Henrich H, Niggemann B et al (2011) Diabetogenic glucose and insulin concentrations modulate transcriptome and protein levels involved in tumour cell migration, adhesion and proliferation. British J Cancer 104:345-352

35. Zhao Y, Hu X, Liu Y, Dong S, Wen Z, He W et al (2017) ROS signaling under metabolic stress: cross-talk between AMPK and AKT pathway. Mol Cancer 16:79
36. Hardie DG, Hawley SA, Scott JW (2006) AMP-activated protein kinasedevelopment of the energy sensor concept. J Physiol 574:7-15

37. Xiang X, Saha AK, Wen R, Ruderman NB, Luo Z (2004) AMP-activated protein kinase activators can inhibit the growth of prostate cancer cells by multiple mechanisms. Biochem Biophys Res Commun 321:161-167

38. Evans JM, Donnelly LA, Emslie-Smith AM, Alessi DR, Morris AD (2005) Metformin and reduced risk of cancer in diabetic patients. BMJ 330:1304-1305

39. Jiang $X$, Tan HY, Teng S, Chan YT, Wang D, Wang N (2019) The role of AMPactivated protein kinase as a potential target of treatment of hepatocellular carcinoma. Cancers 11:647

40. Phielix E, Szendroedi J, Roden M (2011) The role of metformin and thiazolidinediones in the regulation of hepatic glucose metabolism and its clinical impact. Trends Pharmacol Sci 32:607-616

41. Viollet B, Guigas B, Sanz Garcia N, Leclerc J, Foretz M, Andreelli F (2012) Cellular and molecular mechanisms of metformin: an overview. Clin Sci 122:253-270

42. Yang J, Kalhan SC, Hanson RW (2009) What is the metabolic role of phosphoenolpyruvate carboxykinase? J Biol Chem 284:27025-27029

43. Vincent EE, Sergushichev A, Griss T, Gingras MC, Samborska B, Ntimbane T et al (2015) Mitochondrial phosphoenolpyruvate carboxykinase regulates metabolic adaptation and enables glucose-independent tumor growth. Mol Cell 60:195-207

44. Montal ED, Dewi R, Bhalla K, Ou L, Hwang BJ, Ropell AE et al (2015) PEPCK coordinates the regulation of central carbon metabolism to promote cancer cell growth. Mol Cell 60:571-583

45. He L, Li Y, Zeng N, Stiles BL (2020) Regulation of basal expression of hepatic PEPCK and G6Pase by AKT2. Biochem J 477:1021-1031

46. Guo D, Bell EH, Mischel P, Chakravarti A (2014) Targeting SREBP-1-driven lipid metabolism to treat cancer. Curr Pharm Des 20:2619-2626

47. Jeon SM (2016) Regulation and function of AMPK in physiology and diseases. Exp Mol Med 48:e245

48. Nickels JT Jr (2018) New links between lipid accumulation and cancer progression. J Biol Chem 293:6635-6636

49. Guo D, Prins RM, Dang J, Kuga D, Iwanami A, Soto H et al (2009) EGFR signaling through an Akt-SREBP-1-dependent, rapamycin-resistant pathway sensitizes glioblastomas to antilipogenic therapy. Sci Signal 2:ra82

50. Guo D, Reinitz F, Youssef M, Hong C, Nathanson D, Akhavan D et al (2011) An LXR agonist promotes glioblastoma cell death through inhibition of an EGFR/AKT/SREBP-1/LDLR-dependent pathway. Cancer Discov 1:442-456

51. Porstmann T, Griffiths B, Chung YL, Delpuech O, Griffiths JR, Downward J et al (2005) PKB/Akt induces transcription of enzymes involved in cholesterol and fatty acid biosynthesis via activation of SREBP. Oncogene 24:6465-6481

52. Yung MM, Chan DW, Liu WW, Yao KM, Ngan HY (2013) Activation of AMPK inhibits cervical cancer cell growth through AKT/FOXO3a/FOXM1 signaling cascade. BMC Cancer 13:327

53. Karnevi E, Said K, Andersson R, Rosendahl A (2013) Metformin-mediated growth inhibition involves suppression of the IGF-I receptor signaling pathway in human pancreatic cancer cells. BMC Cancer 13:235

54. Zhang F, Chen H, Du J, Wang B, Yang L (2018) Anticancer activity of metformin, an antidiabetic drug, against ovarian cancer cells involves inhibition of cysteine-rich 61 (cyr61)/Akt/mammalian target of rapamycin (mTOR) signaling pathway. Med Sci Monit 24:6093-6101

55. Kimura N, Tokunaga C, Dalal S, Richardson C, Yoshino K, Hara K et al (2003) A possible linkage between AMP-activated protein kinase (AMPK) and mammalian target of rapamycin (mTOR) signalling pathway. Genes Cells 8: 65-79

56. Morgensztern D, McLeod HL (2005) PI3K/Akt/mTOR pathway as a target for cancer therapy. Anticancer Drugs 16:797-803

57. Takano A, Usui I, Haruta T, Kawahara J, Uno T, Iwata M et al (2001) Mammalian target of rapamycin pathway regulates insulin signaling via subcellular redistribution of insulin receptor substrate 1 and integrates nutritional signals and metabolic signals of insulin. Mol Cell Biol 21:5050-5062

\section{Publisher's Note}

Springer Nature remains neutral with regard to jurisdictional claims in published maps and institutional affiliations. 